\title{
Cementing Sharps Safety in the European Union: The Importance of Complying with the 2010 EU Council Directive on Sharps Injury Prevention
}

\section{Alexander Alonso}

Business Management Site Leader and Medical Surgical Systems Country Business Director Benelux, United Kingdom.

"Corresponding author: Alexander Alonso, Business Management Site Leader and Medical Surgical Systems Country Business Director Benelux, London, United Kingdom, Tel: +44 (0)207 402 0510; E-mail: cordelia@lindsellmarketing.com

Received date: February 13, 2014, Accepted date: May 30, 2014, Published date: June 3, 2014

Copyright: () 2014 Alonso A. This is an open-access article distributed under the terms of the Creative Commons Attribution License, which permits unrestricted use, distribution, and reproduction in any medium, provided the original author and source are credited.

\begin{abstract}
The EU Directive on Sharps Injury Prevention in the Healthcare and Hospital Sector (Council Directive 2010/32/EU came into force in all EU member states on 11 $11^{\text {th }}$ May 2013. To ensure its success it is important that all medical and surgical personnel across Europe are aware of, and comply with, the legislation that has come into force as a result. This article discusses the impact that sharps injuries can have on a healthcare worker and their employer, the requirements of the EU Directive, as well as the best practices that healthcare organisations should adopt in order to create a safe working environment for their staff.
\end{abstract}

Keywords Healthcare worker safety; Sharps injury; Council directive 2010/32/EU; Safety engineered-medical devices

\section{Commentary}

In 2010, it was estimated that one million sharps injuries occurred in the European Union each year. This prompted the European Council to adopt a Directive on sharps injury prevention in the healthcare and hospital sector $[1,2]$.

Occupational exposure can be split into two types: percutaneous injuries and mucocutaneous exposure. A percutaneous injury is a break to the skin caused by a needlestick or sharp contaminated with blood or bodily fluid [3]. Mucocutaneous exposure occurs when body fluids come into contact with non-intact skin such as that found in eczema, open wounds, or mucous membranes such as the mouth and eyes [3].

There are several factors which can influence the risk of a sharps injury. Such factors include: the types of device used and procedures undertaken, the quality of training in the safe use and disposal of needles and sharps, and knowledge of the consequences of sustaining such an injury. It must be reiterated to all those that come into contact with sharps that although an injury may appear insignificant, it must be reported and met with appropriate testing and treatment. An injury could result in an infection from 30 potentially dangerous blood-borne pathogens such as Hepatitis B, Hepatitis C and HIV [4].

The EU Directive set out a new legal framework for the management of sharps and needlestick injuries to help ensure a safer working environment for those at risk of sharps injuries. All EU member states were mandated to transpose the Directive into national law by $11^{\text {th }}$ May 2013. Compliance required the establishment of integrated policies in prevention and control and the implementation of follow up and response procedures.

The Directive specifies that healthcare organisations should conduct a formal risk assessment, and, where there is a risk of injuries with a sharp and/or infection, workers' exposure must be eliminated by taking measures to specify and implement safe procedures for using and disposing of sharp medical instruments and contaminated waste. This includes eliminating the unnecessary use of sharps by implementing changes in practice and, on the basis of the results of the risk assessment, providing medical devices incorporating safetyengineered protection mechanisms, as well as banning the recapping of needles.

National legislation incorporating the Directive has now been published in most European countries. For example, the Netherlands was particularly forward thinking in transposing the Directive in early 2011, two years prior to the deadline. The United Kingdom and Belgium passed legislation in May 2013, and Spain followed suit in July of the same year. However, it is understood that (at time of writing) some countries such as Cyprus, Austria, Luxembourg and Ireland are yet to implement the Directive.

The application of the EU Directive was arguably a milestone moment in ensuring healthcare worker safety in Europe. Its level of implementation, however, has varied across the member states. Some failed to meet the initial deadline, while others have, at this stage, struggled to strictly enforce new legislation. To ensure the success of the Directive, it is important that all medical and surgical personnel are aware of, and comply with, the legislation that has come into force as a result.

The impact of an injury on an individual, and potentially a workforce, is not to be underestimated. Even if a sharps injury does not result in seroconversion to a blood-borne pathogen, the traumatic psychological impact [5] can last for months and affect family and personal relationships, as well as impact on ability to perform at work. Career-limiting fear, excessive anxiety, and depression are all acknowledged consequences [6]. Of course the legislation strives for the reduction of sharps injuries regardless of whether a person seroconverts or not, therefore a healthcare organisation that does not reduce its sharps injury rate does not comply with the legislation.

Staff must feel comfortable that there are appropriate measures in place for all staff to dispose of sharps correctly, as well as report an injury. Being denied safety-engineered devices and/or the absence of an effective education and reporting processes could be demoralising 
Citation: Alonso A (2014) Cementing Sharps Safety in the European Union: The Importance of Complying with the 2010 EU Council Directive on Sharps Injury Prevention. J Nurs Care 3: 169. doi:10.4172/2167-1168.1000169

Page 2 of 2

for a workforce and impact on the reputation of a healthcare institution. Injuries can also have a financial impact on an institution as the treatment cost of a staff nurse sustaining a sharp injury can range from $£ 118$ to $£ 7,298$ [6].

Most of the resulting legislation from the EU Directive requires employers to use safety-engineered medical sharps where there is a risk of injury or infection, and provide information and training to employees at risk of sharps injury. Independent studies show that a combination of training, safer working practices, and the use of safetyengineered medical devices can prevent more than 80 per cent of needlestick injuries [7].

The term 'safer sharp' can be defined as "medical sharps that incorporate features or mechanisms to prevent or minimise the risk of accidental injury [8]." Safety-engineered medical devices for the prevention of sharps injuries include, but are not limited to: "Syringes with guards or sliding sheaths that shield the attached needle after use; needles that retract into a syringe after use; shielded or retracting catheters used to access the bloodstream for intravenous administration of medication or fluids; intravenous medication delivery systems that administer medication or fluids through a catheter port or connector site using a needle that is housed in a protective covering, blunt suture needles; and plastic (instead of glass) capillary tubes" [9].

To establish a safety culture across Europe, adhering closely to the legal framework set out by the Directive, and the subsequent legislation of the member states, will dramatically decrease the threat of sharps injuries. Healthcare institutions must unite in their duty of care and create a safe working environment for their employees. Proper enforcement of legislation, and consequences for failing to comply, will enable the European Union to move forward so that sharps injuries that are still rife, will become a rarity.

\section{References}

1. EU Council (2010), EU Council Directive 2010/32/EU.

2. EU Commission for Employment (2010) Social Affairs and Inclusion, 'New legislation to reduce injuries for 3.5 million healthcare workers in Europe'.

3. Haiduven DJ, Simpkins SM, Phillips ES, Stevens DA (1999) A Survey of Percutaneous/Mucocutaneous Injury Reporting in a Public Teaching Hospital, Journal of Hospital Infection, 2: 151-154.

4. European Biosafety Network, Prevention of sharps injuries in the hospital and healthcare sector: Implementation guidance for the EU Framework Agreement Council Directive and Associated National Legislation

5. Green B, Griffiths EC, (2013) Psychiatric consequences of needlestick injury, Occupational Medicin 63: 183-188.

6. Costigliola V, Frid A, Letondeur C, Strauss K (2012) Needlestick Injuries in European Nurses in Diabetes. Diabetes and Metabolism 1: S9-S14.

7. De Raeve P, European Federation of Nurses Associations, Sharps Injuries - Stepping up to the Challenge in Europe.

8. Health and Safety Executive (2013) Health and Safety (Sharps Instruments in Healthcare) Regulations 2013 - Guidance for employers and employees.

9. Occupational Safety and Health Administration (2001) Enforcement Procedures for the Occupational Exposure to Bloodborne Pathogens. 